\title{
Psychological and social evaluation in cases of deliberate self-poisoning admitted to a general hospital
}

\author{
R GARDNER， R HANKA， V C O'BRIEN， A J F PAGE， R REES
}

British Medical fournal, 1977, 2, 1567-1570

\section{Summary}

In a prospective clinical trial 312 cases of self-poisoning (276 patients) consecutively admitted to hospital were randomly allocated to medical teams or to psychiatrists for an initial psychiatric assessment and a decision as to "disposal." Junior doctors and nurses received some instruction in this work. Both groups of assessors asked for help from social workers when necessary. Once the medical teams had completed their assessments, psychiatrists provided most of the hospital treatment. Follow-up at one year showed no significant difference between the two groups of patients in the numbers who repeated their self-poisoning or self-injury (or both), or committed suicide.

Provided junior doctors and nurses are taught to assess self-poisoned patients, we think medical teams can evaluate the suicidal risk and identify patients requiring psychiatric treatment or help from social workers, or both. Contrary to the Department of Health's recommendation that all cases of deliberate self-poisoning should be seen by psychiatrists, we have reached the conclusion that physicians should decide for each of their patients if specialist psychiatric advice is necessary.

\footnotetext{
Self Poisoning Unit, Addenbrooke's Hospital, and Fulbourn Hospital, Cambridge

R GARDNER, MRCP, MRCPSYCH, consultant psychiatrist

V C O'BRIEN, CQSW, senior social worker

R REES, BA, research assistant

University of Cambridge, Department of Community Medicine, Addenbrooke's Hospital, Cambridge CB2 2QQ

R HANKA, MA, MSC, university lecturer in medical statistics

University of Birmingham, Department of Medicine, East Birmingham Hospital, Birmingham B9 5ST

A J F PAGE, MB, MRCP, lecturer in cardiology
}

\section{Introduction}

The Department of Health recommend ${ }^{12}$ that in all cases of deliberate self-poisoning patients should be referred to designated treatment centres in district general hospitals and seen by psychiatrists. This plan has not been fully implemented. General practitioners do not send all such patients to hospital. ${ }^{3}$ There are few special treatment centres for poisoning, and some hospitals lack psychiatric units. Arrangements for assessing these patients vary. In general hospitals where psychiatrists provide a service, many self-poisoned patients are not seen by them. ${ }^{45}$

Opinions differ as to the necessity for psychiatrists to see all such patients. Schmidt, O'Neal, and Robins ${ }^{6}$ considered that some knowledge of psychiatric disorders is necessary to evaluate suicidal risk, though special techniques and training are not. Greer and Bagley, ${ }^{4}$ however, concluded in a retrospective study that one or more interviews with a psychiatrist reduced the incidence of repetition of self-poisoning and of suicide. This conclusion has since been criticised on methodological grounds. ${ }^{7} \times$ Crammer $^{9}$ has questioned the use of scarce specialist resources for assessment, and suggested that house physicians with the help of social workers might identify patients requiring further treatment. We have tried to resolve this issue in a prospective clinical trial.

\section{Patients and methods}

Since there was no special ward for treating self-poisoned patients in old Addenbrooke's Hospital all patients with acute medical conditions went to a single ward. Patients entered the trial if they were aged 15 or more and had been admitted between 12 October 1974 and 31 May 1975 for self-poisoning by drugs (including non-ingestant substances and gases) or alcohol, or both, with or without an accompanying self-injury.

On admission each patient was randomly allocated to a medical team $(\mathrm{M})$ or to a psychiatrist $(\mathrm{P})$, who made an initial psychiatric assessment and decided whether psychiatric treatment in hospital or in the outpatient clinic was necessary and whether help from social workers was needed, or whether the patient should be referred to the general practitioner. Randomisation was effected by entering patients' names on a list of $\mathrm{M}$ and $\mathrm{P}$ allocations drawn up from a table of 
random numbers. Two cases were excluded from the trial because of incorrect diagnoses (epilepsy, meningitis). Patients who repeated their self-poisoning and were readmitted to Addenbrooke's between the above dates were reallocated in the trial.

On the wards the unit social worker or research psychiatrist asked each patient's permission to complete a questionnaire; to allow the research assistant to follow them up at home in six months and one year; and for their general practitioner to be contacted then. Social and psychiatric data obtained by questionnaire were collected for the trial, and, because they were not made available to the medical or psychiatric assessors, did not affect their decisions.

\section{ASSESSMENT}

Senior registrar and consultant psychiatrists from Fulbourn Hospital had attended Addenbrooke's for a decade to assess selfpoisoned patients. All 12 psychiatrists currently on the duty rota took part in the trial. There were seven medical teams under their respective consultant physicians. AP acted as co-ordinator. Preregistration house physicians and medical registrars were instructed in the principles of a psychiatric assessment by RG. They were asked to note their clinical findings in the case notes as for any other patient, and to write a brief formulation. Examples were provided in a handout; this included an article on suicide by Sainsbury. ${ }^{10}$ The nursing staff contributed to the medical teams' assessments, as well as seeing relatives and arranging for the discharge or transfer of the two groups of patients. Both groups of assessors could obtain help from social workers if necessary-psychiatrists from social workers attached to the psychiatric department; medical teams from the self-poisoning unit (VO'B), or from medical social workers.

After assessing each patient the medical teams and psychiatrists indicated their choice of diagnosis (illness and personality) and disposal on a form which they dated and signed. If patients were already receiving psychiatric treatment at the time of their overdose, assessors might consult the doctors concerned before making a decision. Having indicated their choice of disposal, the medical teams were given the option of obtaining a psychiatric opinion if they were not confident about their decision. Physicians might overrule psychiatric assessments or opinions if they thought these were not in their patient's interests. Patients were taken out of the trial if opinions differed, so that the disposal could not be attributed to the original assessor, or if premature discharge (death in one instance) precluded assessment.

\section{PSYCHIATRIC TREATMENT AND AFTERCARE}

Psychiatrists made appropriate arrangements for their patients. The medical teams could choose to provide further psychiatric treatment themselves. In practice they mostly transferred patients to Fulbourn Hospital or referred them to psychiatric outpatient clinics, either to psychiatrists who had previously treated them, or in the case of "new" patients, to a special clinic held twice weekly and staffed by a registrar and senior registrar or consultant. The unit social worker arranged help with social work. Regardless of allocation, the medical teams communicated with the general practitioners of all patients discharged from hospital.

\section{TERMINATION OF TRIAL}

Patients completed the trial if they repeated their self-poisoning or self-injury (or both), committed suicide, or went one year without any of these events happening-that is, without relapse. The research assistant (RR) wrote to all patients and visited them in their homes, if possible, at six months and one year after their admissions. Structured interviews were completed and whenever possible, informants seen. General practitioners completed a short questionnaire at six months and one year. When appropriate, social workers and probation officers were contacted and coroners' records scrutinised. Inquiries were made at the Office of Population Censuses about all untraced patients.

\section{Results}

There were 312 consecutive admissions ( 276 patients) to the trial. In 296 instances self-poisoning was deliberate, in nine accidental, and in seven uncertain. The accidental cases included three thought to be due to a!cohol only and two whose sporadic drug misuse was combined with alcohol intake. Three patients had an accompanying selfinjury. There was no difference between the two groups $(\mathbf{M}$ and $\mathbf{P})$ in the distribution of the three types of poisoning. The accidental and uncertain cases were kept in the trial because it had not always been possible to decide at the time of randomisation which type of poisoning had occurred, nor to be certain after further inquiry that deliberate self-poisoning had been excluded.

Admissions outnumbered patients as 24 of them were admitted more than once to the trial. Table I shows the distribution of all admissions and first admissions to the trial, divided into those who stayed in the trial or were taken out of it. (Throughout this paper we refer to all admissions unless stated otherwise.) Significantly more patients allocated to psychiatrists were taken out of the trial. This was mainly because patients discharged themselves from hospital before they could be assessed, but the difference fails to reach significance.

TABLE I-Total number of admissions* and first admissions to trial, and numbers who stayed in trial or were withdrawn

\begin{tabular}{|c|c|c|c|c|}
\hline \multirow{2}{*}{ Status } & \multicolumn{2}{|c|}{ Medical teams } & \multicolumn{2}{|c|}{ Psychiatrists } \\
\hline & $\begin{array}{c}\text { All } \\
\text { admissions }\end{array}$ & $\begin{array}{c}\text { First } \\
\text { admissions }\end{array}$ & $\begin{array}{c}\text { All } \\
\text { admissions }\end{array}$ & $\begin{array}{c}\text { First } \\
\text { admissions }\end{array}$ \\
\hline $\begin{array}{l}\text { Stayed in trial. } \\
\text { Withdrawn from trial }\end{array}$ & $\begin{array}{r}140 \\
11\end{array}$ & $\begin{array}{r}126 \\
9\end{array}$ & $\begin{array}{r}133 \\
28\end{array}$ & $\begin{array}{r}120 \\
21\end{array}$ \\
\hline
\end{tabular}

*24 patients were admitted more than once.

All admissions: $\gamma^{2}=6.38 ; \mathrm{P}<0.02$.

\section{ASSESSMENT}

Psychiatric opinions were requested by the medical teams for 23 $(16 \%)$ of their patients. In most instances they agreed, but in three they differed, and the patients were taken out of the trial (see table II). Of the 133 assessments by psychiatrists, physicians accepted all but five, and these patients were also taken out of the trial (table II). The disposals chosen by the two groups of assessors are shown in table III. The difference between the two groups in numbers of patients assigned to various categories is not significant.

TABLE II-Reasons for withdrawals from trial

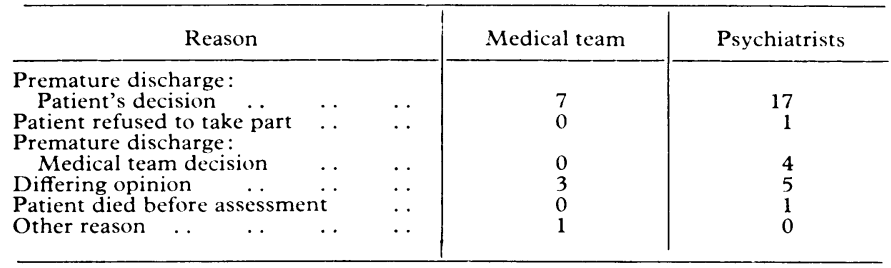

TABLE III-Types of treatment recommended by medical teams and psychiatrists for self-poisoned patients. Number of admissions for which medical teams requested psychiatric opinions are given in parentheses

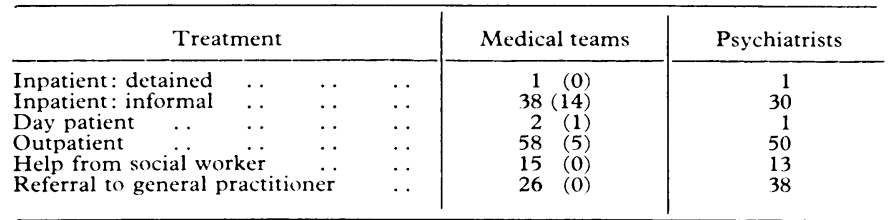

PSYCHIATRIC TREATMENT AND AFTERCARE

Once the assessments had been completed, physicians were not obliged to give any further treatment, though they did so in 16 instances. Most $(90 \%)$ of the subsequent treatment in hospital and in the outpatient clinic was provided by psychiatrists irrespective of the original allocation. Patients received more support from social workers 
than is shown in table III, which shows only the numbers given such help without any other hospital treatment.

As the medical teams could refer their "new" patients to a special clinic, we compared the interval from hospital discharge to the appointment at the outpatient clinic, which was between three to eight days (median of six days), with that for the psychiatrists' own clinics, which was between one to 27 days (median of five days). The intervals seem to differ greatly because a single patient waited four weeks for an appointment at the psychiatric clinic. The difference between the two median times is not significant.

\section{OUTCOME}

Table IV gives details of outcome for all 273 admissions who remained in the trial. The differences in outcome between the two groups are not significant. The proportions of patients surviving without relapse, corrected for drop-outs, are plotted against time in fig 1. The graph seems to show that a slightly larger proportion of the medical teams' patients survived without relapse, but this difference is not significant at any point of the graph $(P>0.05)$. The pro-

TABLE IV-Outcome in both groups after one year. Figures in parentheses refer to first admissions only

\begin{tabular}{|c|c|c|c|c|c|c|}
\hline \multicolumn{5}{|c|}{ Outcome } & \multirow{2}{*}{$\begin{array}{c}\text { Medical teams } \\
82(81) \\
38(28) \\
0(0) \\
20(17)\end{array}$} & \multirow{2}{*}{$\begin{array}{c}\text { Psychiatrists } \\
68(65) \\
43(35) \\
1(1) \\
21(19)\end{array}$} \\
\hline $\begin{array}{l}\text { No relapse } \\
\text { Relapsed } \\
\text { Suicide . . } \\
\text { Drop-out* }\end{array}$ & $\begin{array}{l}\ldots \\
\cdots \\
\cdots\end{array}$ & $\begin{array}{l}\ldots \\
\cdots \\
\cdots\end{array}$ & $\begin{array}{l}. \\
\cdots \\
\ldots\end{array}$ & $\begin{array}{l}\ldots \\
\cdots \\
\cdots\end{array}$ & & \\
\hline
\end{tabular}

*Follow-up incomplete or impossible (see table V).

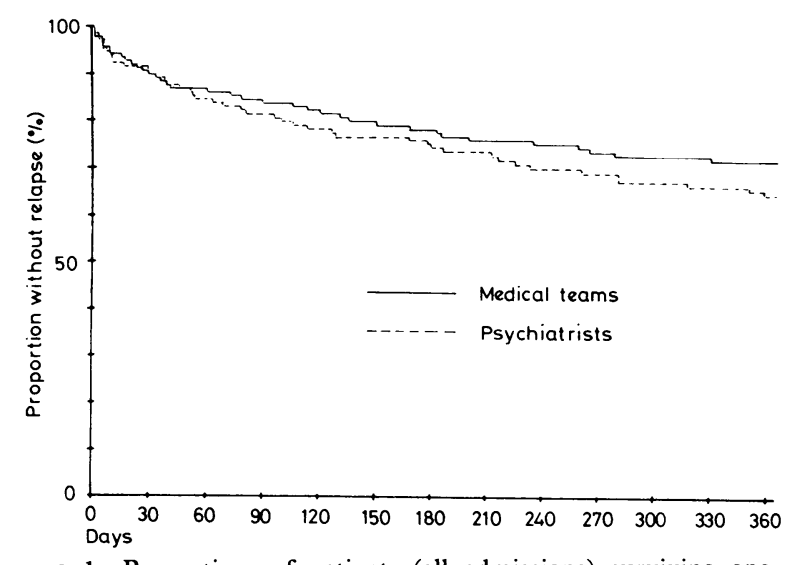

FIG 1-Proportions of patients (all admissions) surviving one year without relapse. Figures corrected for drop-outs.

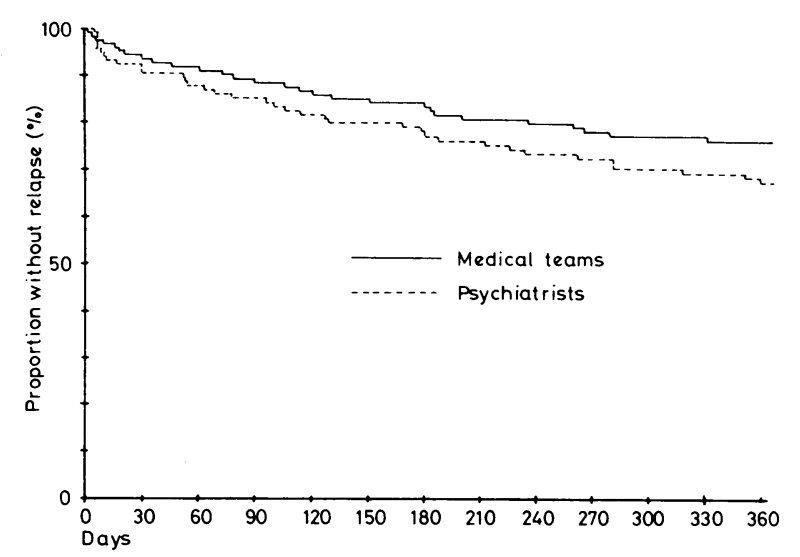

FIG 2-Proportions of patients (first admissions to trial) surviving one year without relapse. Figures corrected for drop-outs. portions of patients surviving one year without relapse are $72.25 \%$ (standard error $(S E)=3.9 \%$ ) and $65 \%(S E=4.3 \%$ ) for $M$ and $P$, respectively.

It might be argued that the overall picture was distorted by reallocating in the trial patients who had already relapsed. Altogether 246 patients were admitted for the first time into the trial. The relevant numbers for these first admissions are given in brackets in table IV.

TABLE v-Reasons for dropping out of trial

\begin{tabular}{|c|c|c|c|}
\hline Reason & & Medical teams & Psychiatrists \\
\hline $\begin{array}{l}\text { No trace since discharge } \\
\text { Partial follow-up only } \\
\text { Refused any follow-up } \\
\text { Refused at one year } \\
\text { Left country } \\
\text { Died* } \\
\text { Di. }\end{array}$ & $\begin{array}{ll}\ldots & \cdots \\
\cdots & \cdots \\
\cdots & \cdots \\
\cdots & \cdots \\
\cdots & \cdots\end{array}$ & $\begin{array}{l}4 \\
7 \\
2 \\
4 \\
2 \\
1\end{array}$ & $\begin{array}{l}3 \\
5 \\
4 \\
6 \\
2 \\
1\end{array}$ \\
\hline
\end{tabular}

${ }^{*}$ Carcinomatosis; postoperatively.

There is no difference in the distribution of the causes of termination of the trial as given in table IV. In fig 2 the relevant proportions of patients surviving without relapse show an even greater difference, but this again is not statistically significant $(\mathbf{P}>0.05)$. One-year survival for those assessed by the medical teams was $76.6 \%(\mathrm{SE}=3.9 \%)$ and $67.9 \%(\mathrm{SE}=4.4 \%)$ for those assessed by the psychiatrists. This consistent difference is interesting, and perhaps warrants further investigation. The reasons for dropping out of the trial (table V) are equally distributed between the two groups.

\section{Discussion}

If specialist psychiatric advice is necessary for all self-poisoned patients ${ }^{12}$ we should have found that patients assessed by the medical teams had fared less well than those assessed by psychiatrists. But this did not happen: there was no significant difference between the two groups in the incidence of relapse during the trial. The medical teams certainly proved to be as effective as the psychiatrists. They identified similar numbers of patients who needed psychiatric treatment in hospital or in the outpatient clinic, or support from social workers. The trial was not designed to compare the efficacy of the treatment given by the two groups of assessors. Once the medical teams had completed their assessments, psychiatrists provided most of the subsequent hospital treatment.

What were the possible sources of bias in the trial which may have affected the comparability of the two groups? If the unit social worker had helped to assess every patient or all those allocated to the medical teams, the similar disposals chosen by both groups of assessors might have been attributed to her. But her participation was limited to patients selected by the medical teams. Had physicians requested psychiatric opinions too readily the whole purpose of the trial would have been nullified. Frequent differing opinions, leading to patients being taken out of the trial, would have left a highly selected group. But neither eventuality occurred. The arrangements for referring "new" patients to the special clinic and to psychiatrists' own clinics differed, but the waiting times were similar for the two groups.

Our findings are in accord with the view ${ }^{6}{ }^{9}$ that a specialist psychiatric training is not essential for the purpose of assessing suicidal risk. They show that too much emphasis need not be placed on the unfavourable attitudes of house physicians, physicians, and to a lesser extent of nurses, towards attempted suicides reported elsewhere. ${ }^{11}{ }^{12}$ At this hospital, a more favourable climate already existed before the trial, and was further helped by the physicians accepting responsibility for half of the assessments. We found that junior doctors and nurses readily learn to evaluate patients' psychosocial problems and to identify the suicidal and the depressed. In deciding why a psychiatric opinion is necessary, instead of always requesting one, they learn some of the indications for and the limitations of psychiatric referral. Similar considerations apply to consultations with social workers. From the outset of the trial we avoided the routine use 
of a social worker to help the medical teams because every patient does not need to see one and social workers are too few to make such a scheme generally applicable. We have since adopted a policy in which the medical teams assess patients initially and ask for advice from psychiatrists and social workers as necessary.

Now that about one in seven ${ }^{1314}$ of all acute medical admissions are for self-poisoning, it is increasingly impracticable for each of them to receive a specialist psychiatric evaluation. This policy ${ }^{2}$ has discouraged the training of our future doctors and nurses because it relies so much on specialist advice. Consequently, many doctors who will later have to evaluate suicidal risk and decide whether or not to prescribe for psychologically distressed patients may be ill-equipped to do so. There is another reason why the management of attempted suicides in the general hospital is of such importance in medical education. As Stenge ${ }^{15}$ pointed out, trainee doctors and nurses can be shown that to preserve life they must concern themselves not only with their patients' physical condition, but also with their psychological and social problems.

We conclude that there is a strong case for amending the recommendation in the Hill Report ${ }^{2}$ so that physicians may decide in each case of deliberate self-poisoning whether a psychiatric opinion is necessary. A selective approach would allow scarce specialist resources to be used more effectively. Psychiatrists might teach junior staff to assess these patients and might concentrate more on improving the treatment and aftercare services, perhaps by organising them by districts. Increasing attention to medical education in this field would contribute to the general training of doctors and nurses, as well as to the prevention of poisoning.

This project (No 79/80) was financed by the East Anglian Regional Health Authority. We thank the consultant physicians at Addenbrooke's Hospital and the consultant psychiatrists at Fulbourn Hospital for permission to interview their patients; the nursing staff at Addenbrooke's, particularly Sister P Mountford, for their participation; general practitioners for completing questionnaires; and Professor I H Mills for his advice and comments.
Medical teams: Drs K Ashley, S Atkinson, S Birch, C Bowman, T C Chalmers, $S$ Chinnock Jones, $N$ Choudhary, $M$ F Chung, $P$ J Ciclitira, J C Cormack, M Couriel, P Crouch, M Davie, A Davies, $M K$ Davies, R G Dent, A P Dick, O M Edwards, D B Evans, M J Farthing, A Ford, M Gawel, J O Hunter, J R Jenner, R J Jung, R Kirby, R Machell, B McLeod, N I McNeill, N J McPherson, W M Malcolm, D Marsh, H Mason, L C Martin, B E Monk, C Olczak, R Peacock, R C Pletts, P Plowman, T B Rosenbaum, $P$ Rowan, E Rowland, C Royce, D Rubinstein, $M$ Rudolf, S H Sachs, P Salt, B Sandhu, M Shooter, A Soulati, J Stuart, S A Tomlinson, $J$ Treleaven, $M$ Whalley, $M$ Wheeler, $N$ Wickham, S Wilkinson, Professor I H Mills.

Psychiatrists on rota: Drs D H Clark, B W Davy, O E F Hodgson, J McKeown, A R K Mitchell, D J Muller, G M Petrie, J M Werner, J C Wilkinson, $R$ W Williams, $R$ Young, B B Zeitlyn.

Psychiatrists in "special" clinic: G R Nayani and R W Williams.

\section{References}

${ }^{1}$ Ministry of Health, HM (61), 94.

2 Central and Scottish Health Services Councils, Hospital Treatment of Acute Poisoning. London, HMSO, 1968.

${ }^{3}$ Kennedy, P, and Kreitman, N, British Fournal of Psychiatry, 1973, 123, 23.

${ }^{4}$ Greer, S, and Bagley, C, British Medical fournal, 1971, 1, 310.

${ }^{5}$ Collier, J, Cummins, T A, and Hamilton, M, fournal of the Royal College of Physicians, 1976, 10 (4), 381.

${ }^{6}$ Schmidt, E H, O'Neal, P, and Robins, E, Fournal of the American Medical Association, 1954, 155 (6), 549.

'Retterstol, N, Life-Threatening Behaviour, 1974, 4 (4), 203.

${ }^{8}$ Welu, T C, and Picard, K M, Proceedings of the 7th International Conference for Suicide Prevention, p 447. Amsterdam, Swets and Zeitlinger, BV, 1974.

${ }^{9}$ Crammer, J L, British Medical fournal, 1969, 2, 651.

1" Sainsbury, P, Medicine, 1974, 30, 1772

${ }^{11}$ Patel, A R, British Medical fournal, 1975, 2, 426.

12 Ramon, S, Bancroft, J H J, and Skrimshire, A M, British fournal of Psychiatry, 1975, 127, 257.

${ }^{13}$ Lawson, A A H, and Mitchell, I, British Medical fournal, 1972, 4, 153.

${ }^{14}$ Mills, I H, and Eden, M A M, in Man in Urban Environments, ed G A Harrison and J B Gibson. London, Oxford University Press, 1976.

${ }^{15}$ Stengel, E, in Suicidal Behaviours, ed H L P Resnick. London, J and A Churchill Ltd, 1968.

(Accepted 18 October 1977)

\title{
Leucocytosis is not a manifestation of rejection
}

\author{
A S DAAR, P J MORRIS, D O OLIVER
}

British Medical fournal, 1977, 2, 1570-1571

\section{Summary}

The leucocyte response to allograft rejection was retrospectively analysed in 80 rejection episodes that occurred in 50 patients. There was no significant change in leucocyte count in 32 rejection episodes. In 27 there was a fall

\footnotetext{
Nuffield Department of Surgery, University of Oxford, Radcliffe Infirmary, and Transplant Unit, Churchill Hospital, Oxford A S DAAR, MRCP, senior house officer P J MORRIS, PHD, FRCS, Nuffield professor of surgery D O OLIVER, FRCP, consultant physician
}

\begin{abstract}
in leucocyte count of more than $20 \%$ and in only 21 was there a rise in count of more than $20 \%$.

Thus leucocytosis seems not to be a manifestation of rejection; indeed, it is the least common response, a fall in the count being commoner. The results also suggest that the prognosis for the graft is poorer when the leucocyte count falls significantly.
\end{abstract}

\section{Introduction}

It has been suggested for many years that leucocytosis is a manifestation of acute rejection. ${ }^{1-3}$ Others, however, have not found a constant association ${ }^{4}$ and Bastle et al ${ }^{5}$ have recently shown, in a study of 159 rejection episodes, that leucocytosis is the least common finding in rejection and that a fall in the leucocyte count, often to leucopenic levels, is a common response. For these reasons we evaluated the leucocyte response to rejection 